\title{
Effect of thermomechanical treatment on mechanical properties and electrical conductivity of a $\mathrm{CuCrZr}$ alloy
}

\author{
G DURASHEVICH*, V CVETKOVSKI and V JOVANOVICH \\ Metallurgy Department, Copper Institute, 19210 Bor, Yugoslavia
}

MS received 13 November 2000; revised 13 November 2001

\begin{abstract}
The CuCrZr alloy undergoes processes of precipitation during ageing. Besides precipitation hardening the strength is affected by cold deformation which is performed before and after ageing.

The cold deformation $\left(D_{1}\right)$ before ageing accelerates the process of strength hardening, since it induces higher rate of precipitation from the saturated $\alpha$-solid solution. Cold deformation $\left(D_{2}\right)$ after ageing primarily affects the alloy strength.

In this paper the results of the effect of thermomechanical treatment on mechanical properties and electrical conductivity of a CuCrZr alloy are presented. The aim of the paper was to evaluate the most suitable combination of thermomechanical treatment and alloy properties.
\end{abstract}

Keywords. Copper-chromium-zirconium alloy; degree of cold deformation; thermal precipitation during ageing.

\section{Introduction}

Brasses find application in electro technique because of their high electrical and thermal conductivity. But, they find increasing use in car industry, mechanical building, electronics etc. Also, alloys of this system have application for making electrodes for autogene and electro-arc welding.

The electrodes made of ternary CuCrZr alloy have double life, they yield twice the number of welding spot compared to conventional electrodes made of binary $\mathrm{CuCr}$ alloy or CuZr alloy (Nikolaev et al 1978). CuCrZr alloys belong to the group of alloys that have high electrical conductivity and moderately high toughness. Consequently they are suitable for high loading parts such as springs, which conduct electricity, contact wheel, etc.

$\mathrm{CuCrZr}$ alloy after solutionizing has homogenous $\alpha$ structure. Chromium precipitates from saturated matrix into either pure chromium and/or intermediate compound $\mathrm{Cr}_{2} \mathrm{Zr}$ by the process of precipitation during ageing (Kuznecov et al 1979).

The particles of secondary phases, which are precipitated from saturated $\alpha$-solid solution, participate in the mechanism of hardening. Also, particle shape, size and volume fraction influence the mechanism and degree of hardening (Novikov et al 1978). To slow down the alloy softening, it is necessary to decrease the size of particles of precipitate as much as possible and increase its volume fraction (Nikolaev et al 1978).

\footnotetext{
*Author for correspondence
}

The process of thermomechanical treatment is often used for increasing the strength of $\mathrm{CuCrZr}$ alloy. This procedure includes water quenching, cold deformation before ageing $\left(D_{1}\right)$ and precipitation during ageing. The cold deformation after ageing $\left(D_{2}\right)$ is rarely employed. Of course, to reach the best combination of toughness and electrical conductivity it is necessary to make optimal choice of parameters of thermomechanical treatment.

The degree of cold deformation influences the mechanism of hardening, particle size, shape and volume fraction. Time and temperature of solution annealing and time and temperature of precipitation during ageing are the other parameters that are of importance (Novikov et al 1978).

According to some authors (Novikov et al 1978), the particles of precipitation in the shape of stick change into ball shape following fragmenting due to the use of $D_{1}$. Meanwhile, spherodization of particles of precipitation originated during $D_{1}$, could be undesirable specially if it is used in the temperature above recrystallization temperature. In other words, increasing of volume fraction of particles of precipitation is desirable while spherodization is not.

Consequently, the degree of cold deformation has a significant part to play in the process of hardening of the alloy and its characterization. Therefore, in this paper, the effect of different parameters of thermomechanical treatment $\left(D_{1}, D_{2}\right.$, temperature and ageing time $)$ on mechanical properties and electrical conductivity of $\mathrm{CuCrZr}$ alloy during precipitation are examined (Durašević et al 1998). 


\section{Experimental}

The CuCrZr alloy used in this work, had the following chemical composition: $0.6 \mathrm{wt} \% \mathrm{Cr}, 0.09 \mathrm{wt} \% \mathrm{Zr}$, the rest being copper plus other trace elements. $\mathrm{CuCrZr}$ alloy employed conformed to Yugoslav standard JUS C.D12.006.

Alloy was made in middle-frequency induction vacuum furnace into cylindrical ingots $50 \mathrm{~mm}$ in dia. The cast ingots were plastically deformed by forging at $850^{\circ} \mathrm{C}$ to a size of $20 \mathrm{~mm}$ dia. After that, they were cold rolled on calibration rollers and drawn up to $4 \mathrm{~mm}$ dia. size. Then, they were drawn on trolley up to the diameter which depended on cold deformation before $\left(D_{1}\right)$ and after $\left(D_{2}\right)$ ageing.

The solution annealing was done at $950^{\circ} \mathrm{C}$ for $1 \mathrm{~h}$ in nitrogen protected atmosphere. The quenching was done in water to yield $\alpha$-solid solution.

$D_{2}$ was done drawing on trolley with following degrees of deformation: $10 \%, 20 \%, 30 \%, 40 \%$ and $50 \%$.

The ageing was done in nitrogen protected atmosphere at following temperature and time periods: $1.400^{\circ} \mathrm{C}$, $6 \mathrm{~h} ; 2.450{ }^{\circ} \mathrm{C}, \quad 6 \mathrm{~h} ; 3.450^{\circ} \mathrm{C}, \quad 3 \mathrm{~h}$ and $4.500^{\circ} \mathrm{C}$, $3 \mathrm{~h}$.
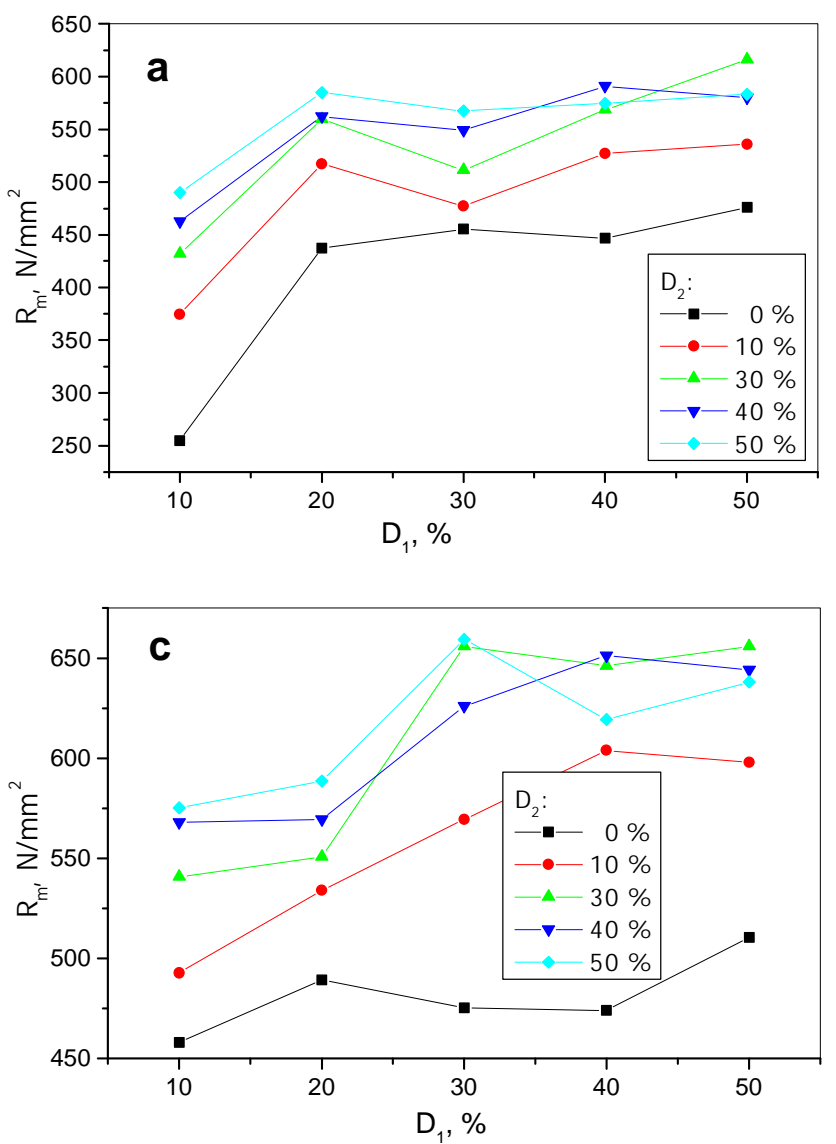

$D_{2}$ was done by drawing on trolley with following degrees of deformation: $0 \%, 10 \%, 30 \%, 40 \%$ and $50 \%$ up to the final diameter of $2 \mathrm{~mm}$.

Samples of all mentioned variants were taken from alloy for mechanical and electrical conductivity examination.

Mechanical properties were evaluated on wire samples of $2 \mathrm{~mm}$ diameter and $300 \mathrm{~mm}$ length (using "Carl Frank" universal machine, Germany test set up).

Toughness, $R_{\mathrm{m}}$ and elongation degree, $A_{200}$ were two parameters which were investigated in this work.

Electrical resistance was measured on samples of wire $2 \mathrm{~mm}$ in dia. and $1000 \mathrm{~mm}$ length. The values of electrical conductivity were calculated from the obtained values of electrical resistance.

\section{Results and discussion}

The mechanical properties and electrical conductivity results are given in figures 1-3.

These results can be investigated to correlate mechanical properties $\left(R_{\mathrm{m}}\right.$ and $\left.A_{200}\right)$ and electrical conductivity. Thus it is seen that $D_{1}$ accelerates precipitation, which is an important factor in alloy hardening.
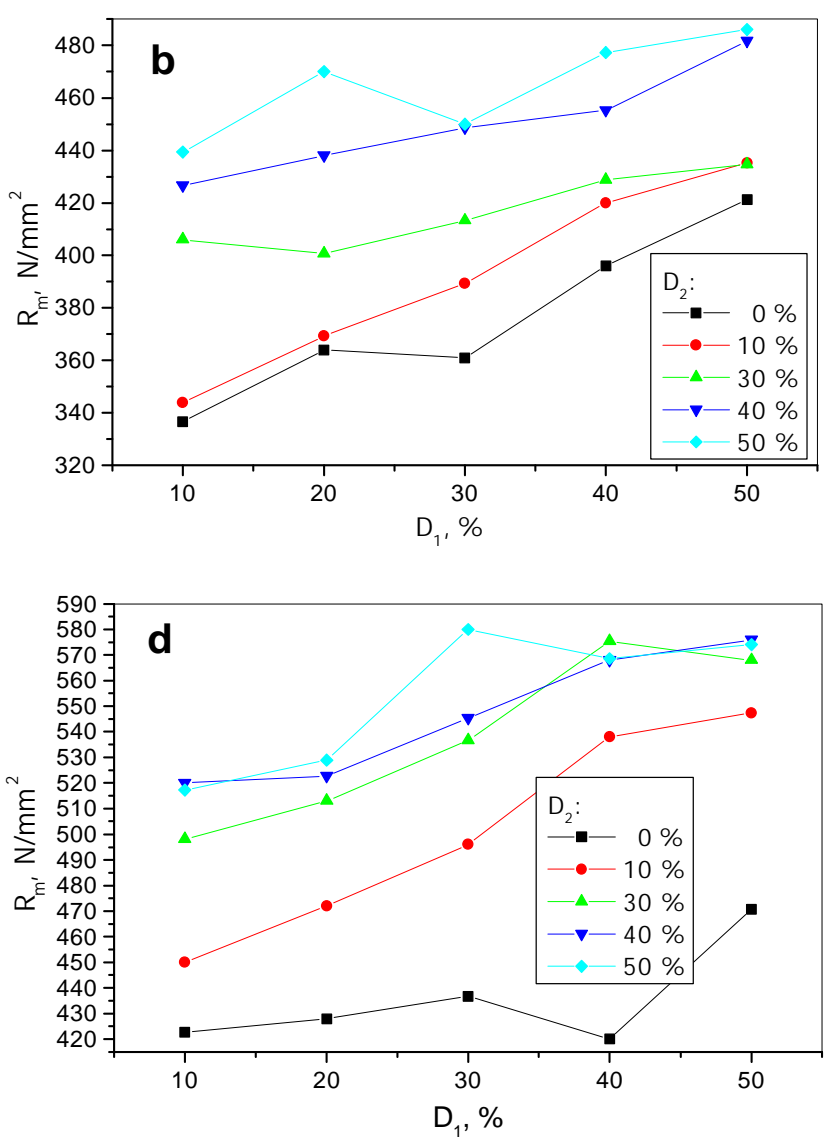

Figure 1. Influence of $D_{1}$ and $D_{2}$ and ageing parameters on $R_{\mathrm{m}}$. a. $400^{\circ} \mathrm{C}$ for $6 \mathrm{~h}, \mathbf{b} .450^{\circ} \mathrm{C}$ for $6 \mathrm{~h}, \mathbf{c} .450^{\circ} \mathrm{C}$ for $3 \mathrm{~h}$ and d. $500^{\circ} \mathrm{C}$ for $3 \mathrm{~h}$. 
With increasing $D_{1}, R_{\mathrm{m}}$ generally increases, while $A_{200}$ decreases, to a small extent and, at the same time, electrical conductivity slightly changes in both directions (figures 1-3).

For the alloy aged at $400^{\circ} \mathrm{C}$ for $6 \mathrm{~h}$ an abrupt increase of $R_{\mathrm{m}}$ (figure $1 \mathrm{a}$ ), electrical conductivity (figure $3 \mathrm{a}$ ) increasing with $D_{1}$ till $20 \%$, while for $A_{200}$ an initial rapid decrease (figure $2 \mathrm{a}$ ), can be noticed. With further increase of the deformation degree, $R_{\mathrm{m}}, A_{200}$ and electrical conductivity slightly changed.

Alloys, aged at $450^{\circ} \mathrm{C}$ for $6 \mathrm{~h}, 450^{\circ} \mathrm{C}$ for $3 \mathrm{~h}$ and $500^{\circ} \mathrm{C}$ for $3 \mathrm{~h}$ show (figures $1 \mathrm{~b}, \mathrm{c}, \mathrm{d}$ ) increasing $R_{\mathrm{m}}$ and slightly decreasing $A_{200}$ (figures $2 \mathrm{~b}, \mathrm{c}, \mathrm{d}$ ) with increasing $D_{1}$. At the same time, electrical conductivity changes slightly in both directions (figures $3 \mathrm{~b}, \mathrm{c}, \mathrm{d}$ ).

Also, noticeable is the fact that $R_{\mathrm{m}}$ shows the highest value at ageing at $450^{\circ} \mathrm{C}$ for $3 \mathrm{~h}$, while fairly satisfactory results can be seen for ageing at $400^{\circ} \mathrm{C}$ for $6 \mathrm{~h}, 500^{\circ} \mathrm{C}$ for $3 \mathrm{~h}$ and $450^{\circ} \mathrm{C}$ for $6 \mathrm{~h}$ (figure 1). $A_{200}$ does not show essential differences, except for samples treated by following regime: $D_{1}=10 \%, 400^{\circ} \mathrm{C}$ for $6 \mathrm{~h}, D_{2}=0 \%$ (figure 2). The highest value of electrical conductivity has samples which are aged at $500^{\circ} \mathrm{C}$ for $3 \mathrm{~h}$, while satisfactory results are obtained on ageing at $450^{\circ} \mathrm{C}$ for $3 \mathrm{~h}$ (figure 3).

Evidently, with increasing $D_{2}, R_{\mathrm{m}}$ increases (figure 1) because of hardening of the alloy.

The highest value of $A_{200}$ is displayed by sample with $D_{2}=0 \%$, while with further increase of $D_{2}, A_{200}$ slightly changes (figure 2). The changing of $\mathrm{D}_{2}$ does not show essential influence on values of electrical conductivity (figure 3).

Based on the above presented data the combinations of thermomechanical treatment, which yielded optimal characteristics, are the following: (a) quenching $\rightarrow 50 \%$ $D_{1} \rightarrow 450^{\circ} \mathrm{C}$ for $3 \mathrm{~h} \rightarrow 40 \% D_{2}$, (b) quenching $\rightarrow 50 \%$ $D_{1} \rightarrow 450^{\circ} \mathrm{C}$ for $3 \mathrm{~h} \rightarrow 50 \% D_{2}$.

The first combination of thermomechanical treatment gave the highest values of toughness $\left(R_{\mathrm{m}}=644 \mathrm{~N} / \mathrm{mm}^{2}\right)$, and electrical conductivity (IACS $=83 \cdot 81 \%$ ), and elongation $\left(A_{200}=1 \%\right)$ is approximately equal to those samples treated by other regimes.
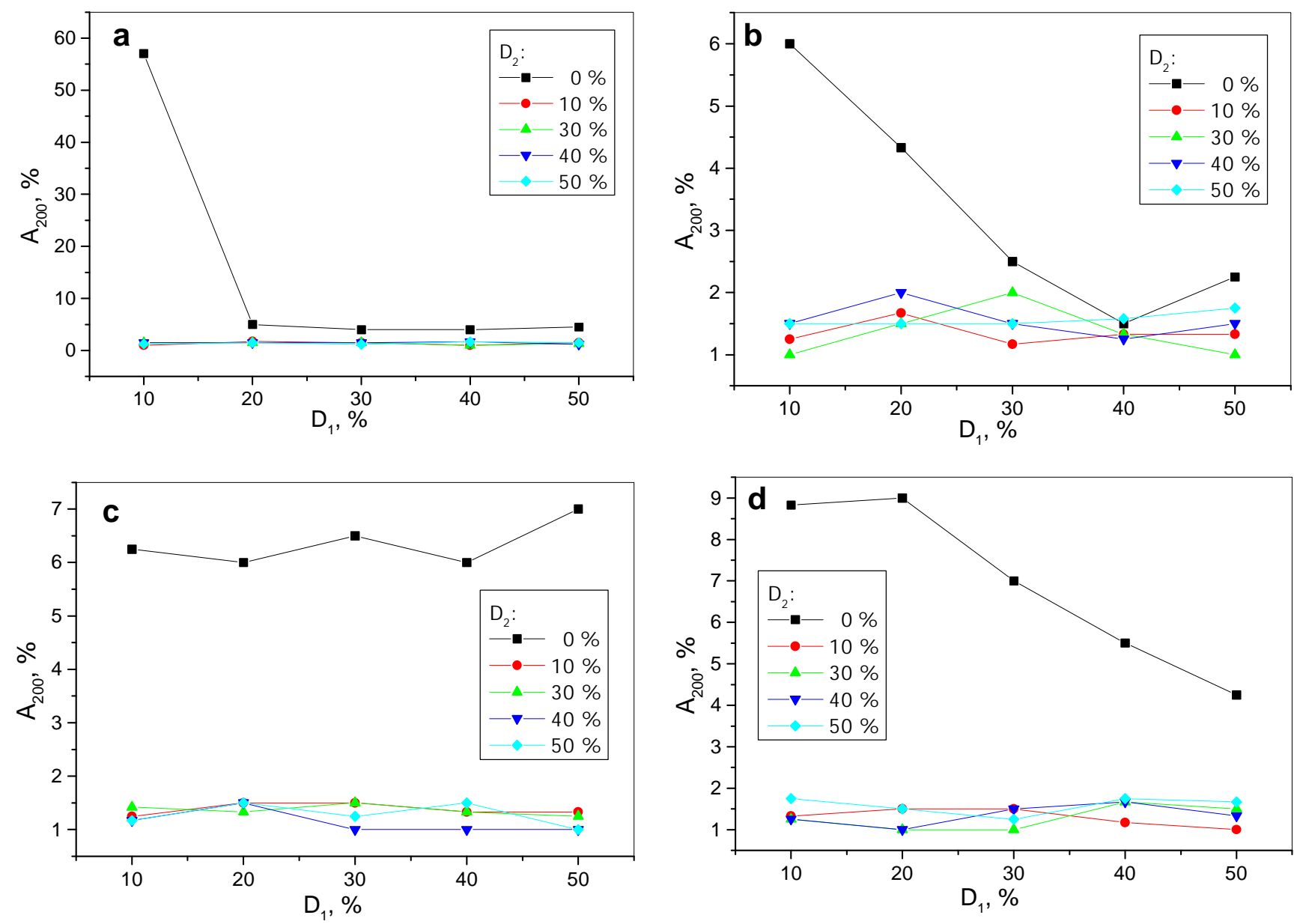

Figure 2. Influence of $D_{1}$ and $D_{2}$ and ageing parameters on $A_{200}$. a. $400^{\circ} \mathrm{C}$ for $6 \mathrm{~h}, \mathbf{b} .450^{\circ} \mathrm{C}$ for $6 \mathrm{~h}, \mathbf{c} .450^{\circ} \mathrm{C}$ for $3 \mathrm{~h}$ and d. $500^{\circ} \mathrm{C}$ for $3 \mathrm{~h}$. 

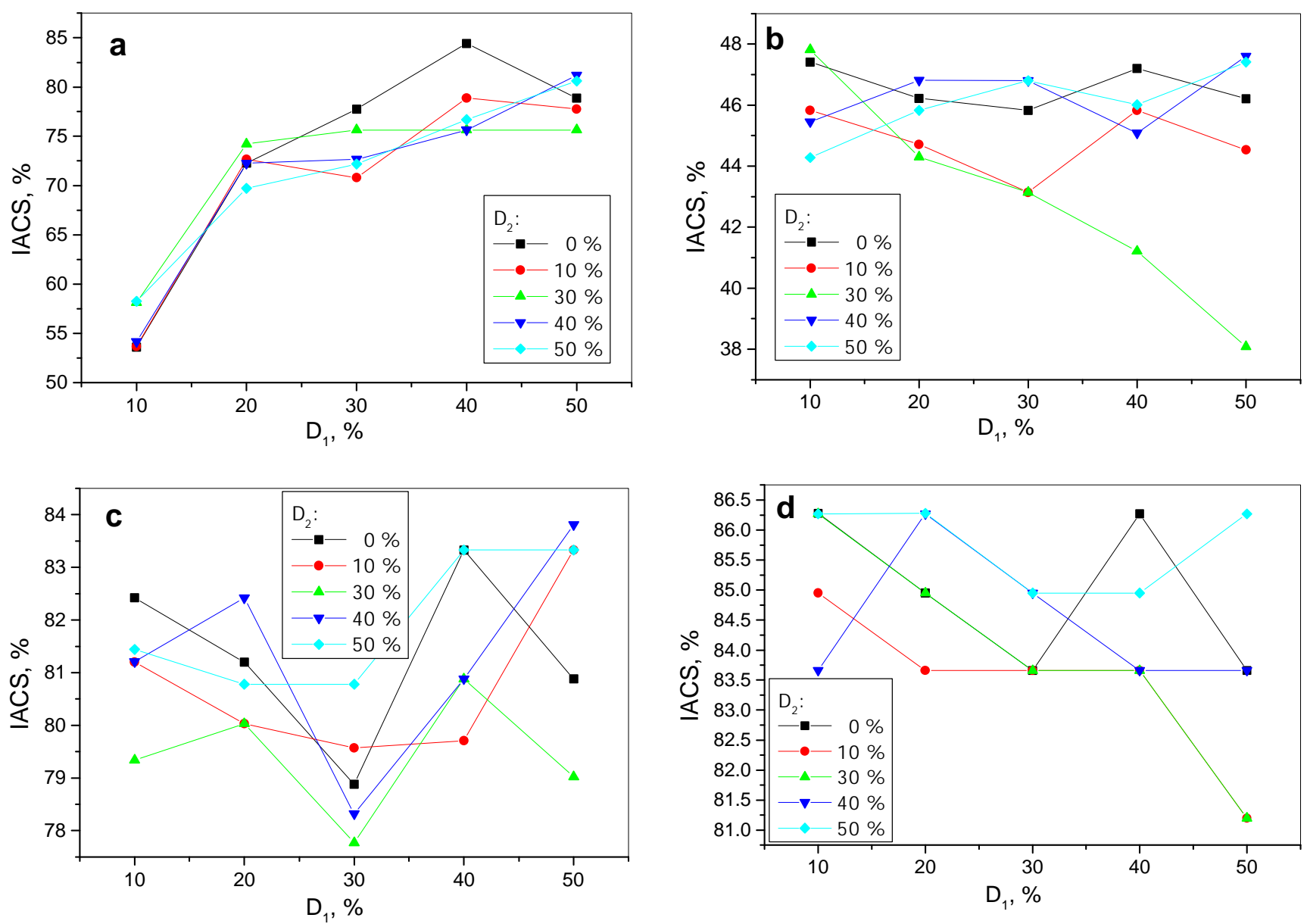

Figure 3. Influence of $D_{1}$ and $D_{2}$ and ageing parameters on electrical conductivity (IACS). a. $400^{\circ} \mathrm{C}$ for $6 \mathrm{~h}, \mathbf{b} .450^{\circ} \mathrm{C}$ for $6 \mathrm{~h}$, c. $450^{\circ} \mathrm{C}$ for $3 \mathrm{~h}$ and d. $500^{\circ} \mathrm{C}$ for $3 \mathrm{~h}$.

The second combination of thermomechanical treatment gave approximately the same values as the first combination $\left(R_{\mathrm{m}}=638 \mathrm{~N} / \mathrm{mm}^{2}, \quad\right.$ IACS $=83.33 \%$ and $A_{200}=1 \%$ ).

\section{Conclusions}

Based on results obtained, the following conclusions can be drawn.

(I) With increasing degree of the cold deformation $D_{1}, R_{\mathrm{m}}$ shows an increase, $A_{200}$ slightly decreases while electrical conductivity changes slightly.

(II) The highest value of $R_{\mathrm{m}}$ is at ageing at $450^{\circ} \mathrm{C}$ for $3 \mathrm{~h}$. $A_{200}$, on the other hand, does not show essential differences. Samples aged at $500^{\circ} \mathrm{C}$ for $3 \mathrm{~h}$ have the highest electrical conductivity.

(III) $R_{\mathrm{m}}$ increases with increasing degree of cold deforma- tion, without essential changes in $A_{200}$ and electrical conductivity.

(IV) The combinations of thermomechanical treatment which gave optimal characteristics are the following: (a) quenching $\rightarrow 50 \% \quad D_{1} \rightarrow 450^{\circ} \mathrm{C}$ for $3 \mathrm{~h} \rightarrow 40 \%$ $D_{2}$, and (b) quenching $\rightarrow 50 \% \quad D_{1} \rightarrow 450^{\circ} \mathrm{C}$ for $3 \mathrm{~h}$ $\rightarrow 50 \% \mathrm{D}_{2}$.

\section{References}

Durashevich G, Todorovic R, Kostav A, Arsenovich M and Ivanich Z 1998 J. Metall. 24123

Kuznecov G M, Fedorov V N, Rodnjanskaja A L and Naumova E A 1979 Cvetnye metally 195

Nikolaev K, Novikov F S, Novikov A I and Rozenberg V M 1978 Cvetnye metally 6111

Novikov A I, Nikolaev A K and Rozenberg V M 1978 Cvetnye metally 6106 